\title{
Pressure-Arching Characteristics of Fractured Strata Structure during Shallow Horizontal Coal Mining
}

\author{
Yanhai ZHAO, Shuren WANG, Youfeng ZOU, Xuchun WANG, Bingqiang HUANG, Xingui ZHANG
}

\begin{abstract}
It is an important problem for the alternated strong and weak roof weighting to threat the safety of working face during shallow coal mining and the total thickness breaking of the thin bedrock to cause the serious ground subsidence. To reveal the mechanism of the abnormal mining damage, the pressure-arching rule in overlying strata was studied. Based on the monitoring data of the typical shallow coal working face, the mechanical models of the symmetrical stress arch, the squeezed arch and the hinged structure of the fractured strata were established, and the difference of the load bearing capacity between the structures and the influencing factors was analysed by the deduced formula calculation. Then the evolution characteristics of the pressure-arch in the fractured strata were revealed by the numerical simulation analysis. The results show that the global pressure-arch of multilayer strata always exits in the surrounding rock and moves forward with continuous mining. The single pressure-arch and hinged structure are formed in each stratum under the global pressure-arch. The pressure-arch enables the fractured strata to carry load efficiently, and the instability of the pressurearch can cause strong roof weighting and ground subsidence. These conclusions provide a theoretical reference for the stability control of the overlying strata structure under shallow coal mining.
\end{abstract}

Keywords: horizontal stress; pressure-arch; shallow coal mining; strata structure

\section{INTRODUCTION}

The large scale mining of shallow coal seam will destroy the thin bedrock and the mining disturbance often causes the fractured strata falling and strong roof weighting, and then the ground subsidence, water loss and soil erosion can damage the ecological environment seriously $[1,2]$. The types and bearing capacity of the blocks structure will affect the strata movement, if grasping the structure evolution characteristics of the overlying strata, and predicting the mining damage by using the structure stability criterion, the roof weighting and the surface movement can be controllable. With the construction and development of the large coal bases in China, the stability control of the overlying strata has become an important issue that needs to be solved urgently for the safety production and environmental protection under the shallow coal mining conditions.

The strong roof weighting during shallow coal mining led to frequent support crushing. This problem was caused by the load bearing structure failure of the overlying strata. The basic roof block slid under the overburden load and strong mine pressure was formed on the support [3]. The stable strata structure can carry the upper overburden load and protect the lower strata. The load bearing capacity of the strata structure is the key factor affecting load transferring among these rock layers, and the efficient bearing load of various blocks structure deserved attention. The self-carrying capacity of the strata was derived from the arching stress, which was delivered from the mid-span to both abutments, and the effect of pressure-arch should be taken into account when analysing the load bearing capacity of the overlying strata. The alternated variation of the roof weighting was caused by the difference of the strata structure types, and the instability of the main load bearing structure would lead to the failure of other structures in advance, so the combined motion of the strata induced the stronger roof weighting [4]. However, the failure mode and migration range of the strata are varied in different mining stages, and the pressure-arch evolution has an important influence on the overall stability and the fractured blocks of the overlying strata, so the structure characteristics of the overlying strata under the influence of pressure-arch should be further studied.

Aiming at revealing the evolution characteristics of the strata structure under shallow coal mining, based on the observed weighting rule of a mining face in Shangwan Mine in Shendong Mining Area in China, considering the influence of the horizontal stress and the arching stress in the overlying strata, the mechanical models of roof blocks were established in different mining stages and the corresponding formulas were deduced to analyse the load bearing capacity of different pressure-arches and the influencing factors. To reveal the evolution rules of the pressure-arch in the surrounding rock and the fractured strata characteristics by using UDEC, the reliability of the mechanical models was verified. The research work will provide a theoretical reference to the strata movement control under shallow coal mining, and it has a guiding significance for the prediction of roof weighting in mining engineering.

\section{STATE OF THE ART}

During the shallow coal mining, the load of the hanging strata was transferred from the mid-span to the two abutments, and the voussoir beam structure was formed by the arching stress in the roof strata. Based on the practical support design for the roof of a deep metal mine, C. C. Li proposed that the pressure-arch could carry load through delivering ground pressure to the surrounding rock [5]. L. He \& Q. B. Zhang investigated the arching mechanism of the pressure-arch and the roof stability during the underground engineering excavation by using DDA technique [6]. M. Shabanimashcool \& C. C. Li conducted the analytical approaches for the stability analysis of voussoir beams by considering the horizontal loading conditions. They found that the maximum stable span of voussoir beams increased with the horizontal stress and the failure mode changed from buckling to crushing with horizontal stress increasing [7]. D. B. Mazor et al. found that the pressure-arch was essential to reach the efficient thickness to sustain the roof stability and the instability 
types of the pressure-arch varied with the block size and stress condition $[8,9]$. Not only these researches indicated the arching mechanism and load bearing capacity of the fractured strata structure, but also they found the stability of the pressure-arch was affected by horizontal stress, buried depth and block sizes.

The previous studies about the load bearing structure in the strata were most concentrated on the rock excavation engineering. For examples, to evaluate the stability of the fractured roof structure, the voussoir beam and the stepped rock beam were applied in analysing the weighting mechanism and the support resistance under shallow coal mining [10-12]. But the horizontal stress boundary and the arching stress were not taken into account in the established models. According to the rock strength and strata thickness in Shendong Mining Area in China, X. Liu et al. pointed out that the weak and laminated strata was unable to form a load-bearing structure, but the strong strata carried the loads of the weak strata, the key stratum could lead to the weak and laminated strata caving $[13,14]$. The large scale mining of shallow coal seam could easily cause the bedrock broken totally, so most researches focused on the research on the basic roof, but they usually ignored the differences of the roof structures and the bearing capacity about different bedrocks, thus the mechanism of long/short and strong/weak weighting under shallow coal mining has not been reasonably revealed.

The overlying strata instability caused by shallow coal mining was common in many countries. A. K. Soni et al. conducted ground subsidence monitoring of shallow cover coal mining by resistance imaging and ground penetrating radar at Kamptee Colliery in India, but the work was limited to monitoring image analysis and lack of the study on the movement rule of overlying strata and the effect of strata structure [15]. The shallow coal mining caused ground subsidence and several crown-holes in Edinburgh in UK, the sinkholes affected the East Coast Main Railway and these accidents led to enormous economic losses. P. R. Helm et al. performed the ground investigation and the numerical modelling to analyse the potential causes of instability, including the level variations of the groundwater table, the influence of the structure of the rock mass, and the geometry of the abandoned mining workings [16]. E. F. Salmi et al. adopted the Tributary Area Method and FLAC3D to investigate the effect of gradual deterioration on the stability of the shallow abandoned room and pillar, and pointed out that the long-term deterioration due to mechanical and chemical factors decreased the strength of pillar and reduced their effective bearing capacity [17]. Based on numerous sudden ground collapse cases in Datong coal field in China, X. M. Cui et al. investigated the mechanism of subsidence induced by shallow partial mining by using the similar material simulation and UDEC technique. They found that the inner stress arches merged the pillar rupture and gradually combined with the external stress arch, and at last, the stress evolution resulted in the sudden collapse at surface [18]. This work only concentrated on the stress evolution among these pillars, but ignored the influence of the strata structure evolution characteristics.

To sum up the above mentioned studies, we found that many results had been achieved about the load bearing structure of stress arch in strata. However, it was not perfect enough about pressure-arching characteristics of the fractured strata during shallow coal mining. So this research will conduct further study on this aspect. The remainder of this study is organized as follows. In Section 3 , the comprehensive research methods, such as engineering background, numerical simulation and theoretical analysis are introduced. In Section 4, the pressure-arching characteristics of the fractured strata structure are analysed during shallow coal mining. Finally, some conclusions are given in Section 5.

\section{METHODOLOGY}

\subsection{Engineering Background}

Taking No. 51104 working face in panel at Shangwan Mine in Shendong Mining Area as background, the working face was at an average depth $115.4 \mathrm{~m}$, the dip angle of the coal was $0-5^{\circ}$, the thickness of coal was 5.03$7.90 \mathrm{~m}$, and the coal average thickness was $6.7 \mathrm{~m}$. The average thickness of the overburden of alluvial sand was $13.70 \mathrm{~m}$, and that of the bedrock was $102.10 \mathrm{~m}$. The immediate roof was mostly sandy mudstone or siltstone, whose thickness was $0.50-7.10 \mathrm{~m}, 3.00 \mathrm{~m}$ in average. The basic roof was sandstone, whose thickness was 6.00-15.10 $\mathrm{m}, 9.00 \mathrm{~m}$ in average. The compressive strength of the basic roof was 16.60-33.80 MPa, $25 \mathrm{MPa}$ in average.

The designed mining height was $5.20-5.50 \mathrm{~m}$, the strike length was $3654 \mathrm{~m}$, the dip length was $301 \mathrm{~m}$, and the advancing length was $3360 \mathrm{~m}$. The inclined longwall backward mining method was adopted matching the German Eickhoff SL-500 shearer, the total caving method was used to manage roof and DBT double column shield electro-hydraulic control supports were arranged to protect the working face. The initial resistance of the support was $6900 \mathrm{kN}$ and the rated working resistance was $8638 \mathrm{kN}$. The top beam length was $4.08 \mathrm{~m}$ and the centre distance among beams was $1.75 \mathrm{~m}$. The initial weighting and nineteen times periodic weighting occurred during the observation period. As shown in Fig. 1, the initial weighting interval was $27.20 \mathrm{~m}$ and the support resistance was $5921.33 \mathrm{kN}$. The periodic weighting interval varied at 9.40-32.3 $\mathrm{m}$ and the support resistance was 5571.69$8974.55 \mathrm{kN}$. The eleventh time weighting exceeded the rated resistance of the support.

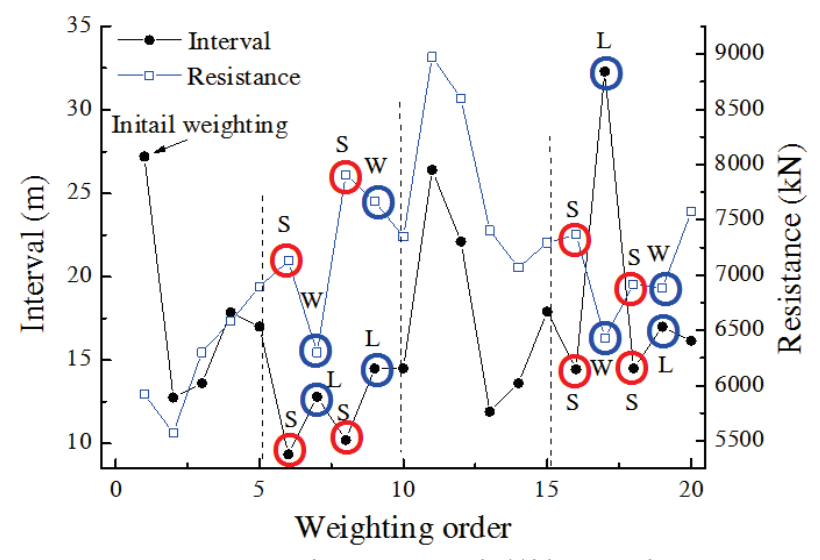

Figure 1 The roof weighting law of 51104 working face

Four times periodic weighting occurred with the working face advancing $61.20 \mathrm{~m}$ after initial weighting, the weighting rule was similar in this stage, and the stronger 
roof weighting appeared with the longer interval. Thereafter, the weighting interval and intensity appeared the alternated regularity of long/short and strong/weak periodically, the long interval corresponded to the weak weighting $(\mathrm{L} / \mathrm{W})$, while the short interval corresponded to the strong weighting $(\mathrm{S} / \mathrm{S})$. The sixth and eighth time weighting was $\mathrm{S} / \mathrm{S}$ type, the seventh and ninth time weighting was $\mathrm{L} / \mathrm{W}$ type. The tenth to fifteenth time weighting appeared with normal regularity, with the working face advancing, while the sixteenth to twentieth time weighting alternated with the long/short and strong/weak law again. There was a long interval between the normal weighting and the alternated long/short and strong/weak weighting.

\subsection{Simplify the Mechanical Model}

In the initial stage of mining, the compressive stress deviated toward the mined-out area under the disturbance of coal mining and showed significant arching effect in the surrounding rock. The global pressure-arch of nonfractured zone was formed to carry the load from overlying strata and self-weight, the arch feet were located in the surrounding rock at the work face and open-off cut side. There was a low pressure area under the shield of the global pressure-arch, the face support was required to prevent the fall of detached basic roof blocks. The removable space and structure characteristics of the key roof blocks were affected by the filling of the caving waste of the immediate roof.

Taking the roof blocks in the initial mining stage as research object is shown in Fig. 2. The roof block $K_{\mathrm{A}}$ was the main key block above the support, the block $K_{\mathrm{B}}$ slid with the displacement $\Delta$ relative to the left vertex of the block $K_{\mathrm{A}}$. Assuming that the thickness of the coal seam was $M$, the thickness of the immediate roof was $\Sigma h$, the rock bulking factor was $K_{\mathrm{p}}$, the displacement $\Delta$ depended on the calculation of $M-\sum h\left(K_{\mathrm{p}}-1\right)$. The hinged structure was formed by the sliding block and main key block in the small movable space. For the large height mining field, the step structure was formed by the sliding blocks with the unequal displacement in the large movable space. The block $K_{\mathrm{A}}$ rotated with the angle $\alpha$, and the half stress arch was formed in the block by the horizontal thrust $T$ from the front rock wall and the rear sliding block using the distribution function of the horizontal stress $\sigma_{x x}$ at the boundary of the block [8]:

$$
\sigma_{x x}=\sigma_{\mathrm{m}}(x-h)^{b}
$$

where $h$ was the distributed height of the horizontal stress at the abutments, $\sigma_{\mathrm{m}}$ was the maximum horizontal stress, and $x$ was the coordinate position.

The horizontal thrust $T$ and its position $X_{T}$ was respectively given by

$$
\begin{aligned}
& T=\frac{\sigma_{\mathrm{m}} h}{b+1} \\
& X_{T}=\frac{h}{b+2}
\end{aligned}
$$

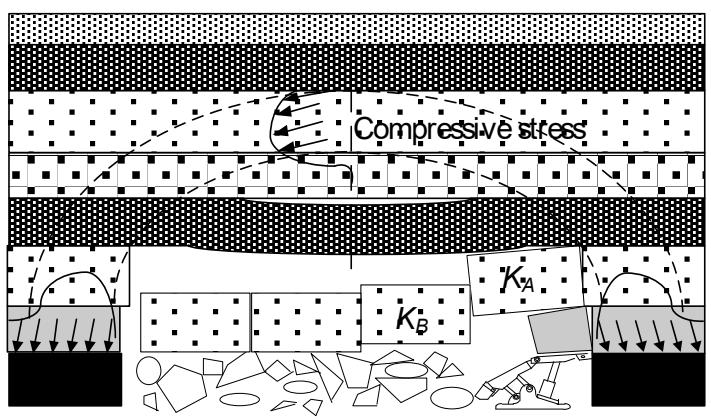

(a) Sketch map of the engineering model

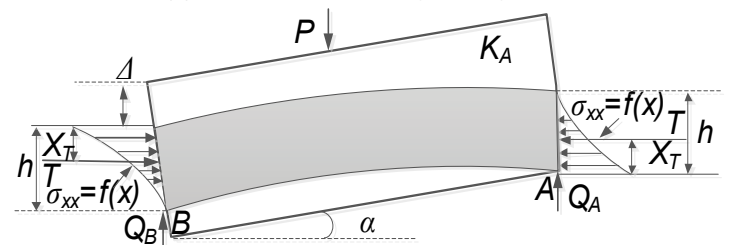

(b) Mechanical model of the main key block

Figure 2 Key blocks of the basic roof and global pressure-arch

The main key block $K_{\mathrm{A}}$ was taken as the object, the block thickness was $H$ and the length was $L$, taking the moment at the right origin point $\mathrm{A}, \Sigma M_{\mathrm{A}}=0$, then

$$
Q_{\mathrm{A}}=0.5 P+T \frac{H-L \sin \alpha-\Delta-2 X_{T}}{L}
$$

When the shear force $Q_{\mathrm{A}}$ was larger than the contacting friction $T \tan \varphi$, the support was required to provide sufficient resistance to prevent sliding of the key block. According to Eqs. (2) and (4), the working resistance $F_{\mathrm{S}}$ of the support was given by the following:

$$
F_{\mathrm{S}}=0.5 P+\frac{\sigma_{\mathrm{m}} h}{b+1}\left(H-L \sin \alpha-\Delta-2 X_{T}-\tan \phi\right)+\gamma L \sum h
$$

If the stress in the global pressure-arch exceeded the rock strength, the strata was fractured and gradually lost its carrying capacity. The global pressure-arch of nonfractured zone developed toward the upper stable surrounding rock, the fractured roof sank and changed into near the mining field area, and the pressure-arch in roof blocks was formed in the initial and periodic roof weighting stage. As shown in Fig. 3a, the symmetrical stress arch was formed under the inner boundary of the global pressure-arch of non-fractured zone in the initial stage of strata separation. After the strata breaking, the symmetrical stress arch still could be maintained by the horizontal stress transferring between the blocks. The rotation and sliding motion of the block in the stress arch structure would increase the load on the lower strata, the successive instability of the symmetrical stress arch in each stratum was the main cause of roof weighting and this type structure first appeared in the initial mining stage. Establishing the mechanical model as shown in Fig. 3b, the thickness of the block $G_{\mathrm{A}}, G_{\mathrm{B}}$ was $H$, the length was $L$, the rotating angle was $\alpha$. Taking the moment at the left point $\mathrm{B}, \Sigma M_{\mathrm{B}}=0$, then

$$
0.5 P_{\mathrm{A}} L+1.5 P_{\mathrm{B}} L-1.5 F_{\mathrm{A}} L-0.5 F_{\mathrm{B}} L-2 Q_{\mathrm{A}} L=0
$$




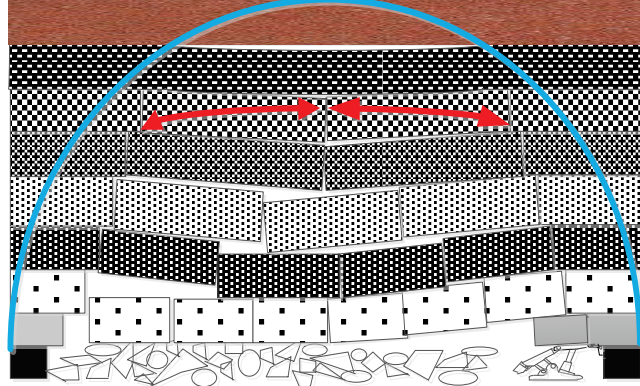

(a) Sketch map of the engineering model

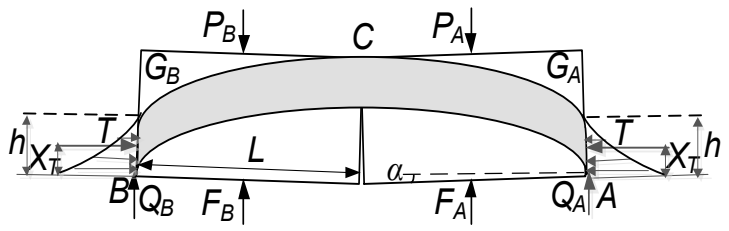

(b) Mechanical model of the symmetrical stress arch

Figure 3 The caving arch of fractured area and global pressure-arch

Taking the moment of the $G_{\mathrm{A}}$ at the middle point $\mathrm{C}$, $\Sigma M_{\mathrm{C}}=0$, then

$T\left(H-L \sin \alpha-2 X_{T}\right)+0.5 P_{\mathrm{A}} L-0.5 F_{\mathrm{A}} L-Q_{\mathrm{A}} L=0$

Considering the symmetry of the structure, the overburden load and the supporting force on the two blocks could be treated as equal, $P_{\mathrm{A}}=P_{\mathrm{B}}=P, F_{\mathrm{A}}=F_{\mathrm{B}}$. Combining Eqs. (6) and (7), the supporting force on the block was given as:

$F_{\mathrm{A}}=P-\frac{2 T\left(H-L \sin \alpha-2 X_{T}\right)}{L}$

As the global pressure-arch of non-fractured zone developed into the loose layer of sand, because of the lower strength of the sand layer, the arching effect vanished gradually with the plastic failure of the loose layer, the ground subsidence appeared and the subsidence basin was formed in the fully mining stage. Thereafter, the hinged structure and the squeezed arch structure existed in the fractured roof under the global pressure-arch of nonfractured zone. As in Fig. 4b, the hinged blocks rotated relatively and delivered load to the lower strata. Establishing the mechanical model of the roof blocks of initial rotating position during periodic roof weighting, the shear force $Q_{\mathrm{N}}$ on the block $B_{\mathrm{N}}$ at the left hinged point $\mathrm{N}$ was applied by the rear compacted block, $Q_{\mathrm{N}}=0$, taking the moment at the left hinged point $\mathrm{N}, \Sigma M_{\mathrm{N}}=0$, and the vertical resultant force $\Sigma F_{y}=0$, then

$$
\begin{aligned}
& T\left(H-L \sin \alpha_{1}-L \sin \alpha_{2}-2 X_{T}\right)+0.5 L\left(P_{\mathrm{M}}-F_{\mathrm{M}}\right)+ \\
& +1.5 L\left(P_{\mathrm{N}}-F_{\mathrm{N}}\right)-2 Q_{\mathrm{M}} L=0 \\
& P_{\mathrm{M}}+P_{\mathrm{N}}-F_{\mathrm{M}}-F_{\mathrm{N}}-Q_{\mathrm{M}}=0
\end{aligned}
$$

Taking the moment of the front block $B_{\mathrm{M}}$ at the middle point $\mathrm{O}, \Sigma M_{\mathrm{O}}=0$, then

$$
0.5\left(P_{\mathrm{M}}-F_{\mathrm{M}}\right)-T \sin \alpha-Q_{\mathrm{M}}=0
$$

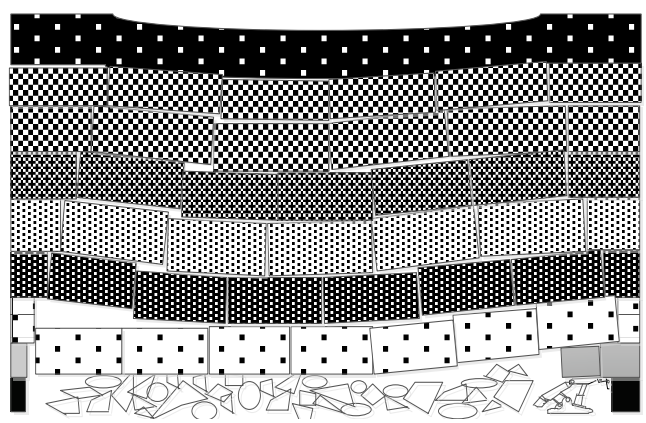

(a) Sketch map of the engineering model

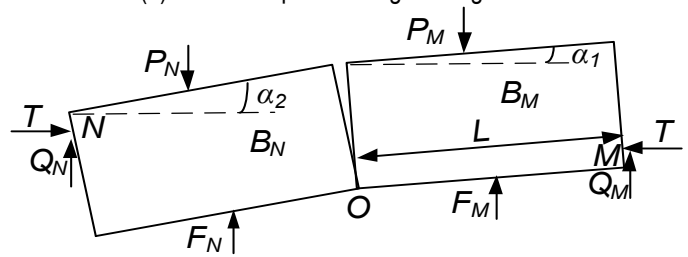

(b) Mechanical model of the hinged structure

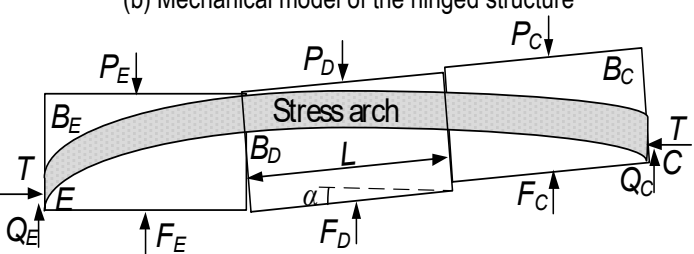

(c) Mechanical model of the squeezed arch structure

Figure 4 The hinged and pressure-arch structure in multilayer overlying strata

This model was the structure with one degree of indeterminacy. Assuming that the carrying load of the two blocks was equal, the equation set could be solved. Let $P_{\mathrm{M}}$ $=P_{\mathrm{N}}=P$, combining Eqs. (9), (10) and (11), the supporting force on the block was given as:

$F_{\mathrm{M}}=P-T\left(\frac{8 X_{T}}{L}+4 \sin \alpha_{2}-4 \frac{H}{L}-2 \sin \alpha_{1}\right)$

As shown in Fig. 4c, the squeezed arch structure was formed by the horizontal thrust between the blocks. The latter arch foot was located in the compacted block $B_{\mathrm{E}}$ which was contacting the waste, establishing the mechanical model of the two blocks in front half arch. For the compacted block $B_{\mathrm{E}}, P_{\mathrm{E}} \approx F_{\mathrm{E}}, Q_{\mathrm{E}}=\frac{T\left(H-2 X_{T}\right)}{L}$, taking the moment at the left supported point $\mathrm{E}, \Sigma M_{\mathrm{E}}=0$, and the vertical resultant force $\Sigma F_{y}=0$, then

$$
\begin{aligned}
& 2 T L \sin \alpha-1.5 P_{\mathrm{D}} L-2.5 P_{\mathrm{C}} L+1.5 F_{\mathrm{D}} L+ \\
& +2.5 F_{\mathrm{C}} L+3 Q_{\mathrm{C}} L=0 \\
& P_{\mathrm{C}}+P_{\mathrm{D}}-Q_{\mathrm{E}}-Q_{\mathrm{C}}-F_{\mathrm{C}}-F_{\mathrm{D}}=0
\end{aligned}
$$

Assuming that the overburden load and the supporting force on the two blocks was equal, $P_{\mathrm{C}}=P_{\mathrm{D}}, F_{\mathrm{C}}=F_{\mathrm{D}}$, combining Eqs. (13) and (14), the supporting force on the block was given:

$$
F_{\mathrm{C}}=P-T \frac{3\left(H-2 X_{T}\right)-2 L \sin \alpha}{2 L}
$$

In the initial mining stage, the symmetrical stress arch occurred in the separated strata near the mining field and 
the global pressure-arch was formed in the non-fractured strata zone far from the mining field. With the working face advancing in the periodic roof weighting stage, the strata near the mining field separated from the non-fractured strata zone and fractured, the hinged structure and squeezed stress arch structure was formed in the broken blocks under the inner boundary of the global pressure-arch of the non-fractured strata zone.

\subsection{Building the Computational Model}

Based on the geological condition and the mining field in Shanwan Mine, the discrete element software UDEC was used to analyse the evolution characteristics of the strata structure under the shallow coal mining condition. The thickness of the coal seam was $7.0 \mathrm{~m}$, total thickness was mined in one time with large height mining technology. The thickness of the floor, the immediate roof, and the basic roof were $10.0 \mathrm{~m}, 4.0 \mathrm{~m}$, and $9.0 \mathrm{~m}$, respectively. The thickness of the strata over the basic roof was set as $95.0 \mathrm{~m}$ and that of the ground sand layer was $12.0 \mathrm{~m}$.

The model sizes were $400.0 \mathrm{~m}$ long and $137.0 \mathrm{~m}$ high. The upper boundary was free, the bottom boundary was fixed, and the lateral boundaries of the model were fixed in the horizontal direction.

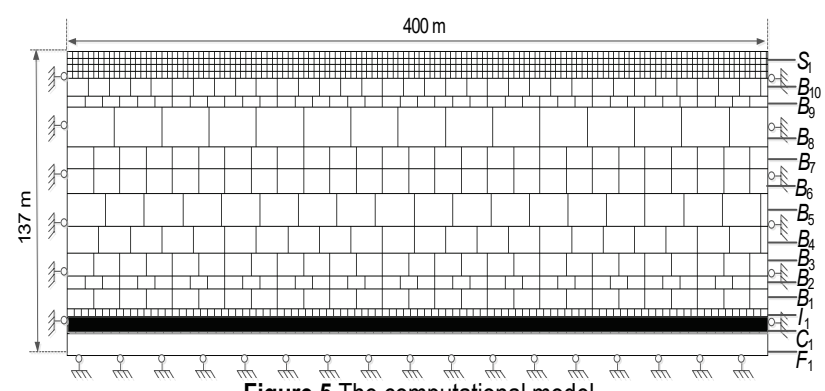

Figure 5 The computational model

( $S_{1}$ : Soil; $B_{2}, B_{4}, B_{5}, B_{7}, B_{9}$ : Sandy mudstone; $B_{3}, B_{6}$ : Coarse sandstone; $B_{1}, B_{8}$ : Sandstone; $I_{1}$ : Mudstone; $C_{1}$ : Coal; $B_{10}, F_{1}$ : Siltstone)

The position of start mining was $50 \mathrm{~m}$ away from the left boundary and the advancing distance was $300 \mathrm{~m}$. Each stratum was arranged with three monitoring lines along the $Y$ direction to obtain the evolution rule of the stress field and displacement field during shallow coal mining. The physical and mechanical parameters of the model were listed in Tab. 1. Mohr-Coulomb criteria were used in the numerical calculation.

Table 1 Physical and mechanical parameters of the materials

\begin{tabular}{|c|c|c|c|c|c|c|}
\hline Name & $\begin{array}{c}\text { Unit weight } \\
\left(\mathrm{kN} / \mathrm{m}^{3}\right)\end{array}$ & $\begin{array}{c}\text { Elastic modulus } \\
(\mathrm{GPa})\end{array}$ & Poisson's ratio & $\begin{array}{c}\text { Cohesive } \\
\text { strength }(\mathrm{MPa})\end{array}$ & $\begin{array}{c}\text { Tensile strength } \\
(\mathrm{MPa})\end{array}$ & $\begin{array}{c}\text { Frictional } \\
\text { angle }\left({ }^{\circ}\right)\end{array}$ \\
\hline Soil & 19.2 & 0.08 & 0.32 & 0.1 & 0.04 & 28 \\
\hline Sandy mudstone & 24.0 & 29 & 0.23 & 3.7 & 2.1 & 35 \\
\hline Coarse sandstone & 24.3 & 35 & 0.21 & 5.5 & 4.0 & 33 \\
\hline Sandstone & 25.0 & 32 & 0.24 & 7.3 & 4.9 & 35 \\
\hline Mudstone & 22.4 & 23 & 0.15 & 2.5 & 1.7 & 30 \\
\hline Coal & 13.1 & 15 & 0.29 & 0.79 & 0.57 & 27 \\
\hline Siltstone & 24.6 & 26 & 0.22 & 3.9 & 2.5 & 38 \\
\hline
\end{tabular}

\section{RESULTS AND DISCUSSION}

Based on the established mechanical models in different mining stages, the load bearing capacity of the fractured strata structure could be analysed. Assuming that the thickness of the overburden layer was $H_{Z}$, the average unit weight was $\gamma$. The pressure $P$ on the block with length $L$ was $\gamma H_{Z} L$, the downward delivering load $q$ of the block was equal to the support force in unit length $F / L$, then the efficient bearing load of the structure was $\gamma H_{Z}-q$. Substituting Eqs. (2) and (3) into Eqs. (8), (12), and (15), then the efficient bearing load $f$ of the symmetrical stress arch structure, the squeezed arch structure and the hinged structure was, respectively,

$$
\begin{aligned}
& f_{\mathrm{A}}=\gamma H_{\mathrm{Z}}-\frac{F_{\mathrm{A}}}{L}=\sigma_{\mathrm{m}} \frac{2 t i}{b+1}\left(i-\sin \alpha-\frac{2 t i}{b+2}\right) \\
& f_{\mathrm{C}}=\gamma H_{\mathrm{Z}}-\frac{F_{\mathrm{C}}}{L}=\sigma_{\mathrm{m}} \frac{t i}{b+1}\left(1.5 i-\sin \alpha-\frac{3 t i}{b+2}\right) \\
& f_{\mathrm{M}}=\gamma H_{\mathrm{Z}}-\frac{F_{\mathrm{M}}}{L}=\sigma_{\mathrm{m}} \frac{t i}{b+1}\left(\frac{8 t i}{b+2}+4 \sin \alpha_{2}-4 i-2 \sin \alpha_{1}\right)
\end{aligned}
$$

where $i=H / L$ was the ratio of the block thickness $H$ to the block length $L$. $t=h / H$ was the ratio of the distributed height of boundary horizontal stress to the block thickness $H$, which represented the arch thickness.

The results of Eqs. (16) to (18) were the products of $\sigma_{\mathrm{m}}$ and dimensionless variables, so that it could be concluded that the efficient bearing load $f$ was the multiple of the maximum boundary horizontal stress $\sigma_{\mathrm{m}}$. The variable $f$ could be simplified as:

$$
f=\gamma H_{\mathrm{Z}}-\frac{F}{L}=K_{\mathrm{S}} \sigma_{\mathrm{m}}
$$

The parameter $K_{\mathrm{S}}$ could be calculated by the function after the variable $\sigma_{\mathrm{m}}$ in Eqs. (16) to (18). $K_{\mathrm{S}}$ was defined as load bearing coefficient to represent the load bearing capacity of the structure.

The symmetrical stress arch and the squeezed arch were the load bearing structures formed by arching distributed stress, the rotating angle $\alpha$ was taken as $5^{\circ}$, the distribution of the boundary horizontal stress was set as: $b$ $=1$ linearly distributed, $b=2$ nonlinearly distributed. According to Eqs. (16) and (17), the coefficient $K_{\mathrm{S}}$ could be calculated under different block size $i$ and arch thickness $t$. As shown in Fig. 6, the coefficient $K_{\mathrm{S}}$ varied as the following: (1) The load bearing coefficient of the symmetrical stress arch was higher than that of the squeezed arch. (2) The load bearing coefficient increased with increasing block size $i$. (3) With the arch thickness $t$ increasing, the load bearing coefficient increased before reaching the maximum value and then decreased. (4) When the boundary horizontal stress was linearly distributed, the load bearing coefficient of the structure was higher. 


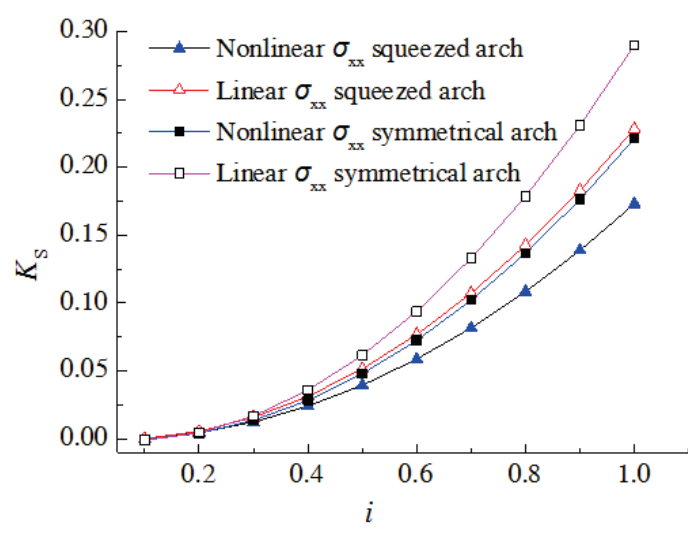

(a) Different block size $i(t=0.5)$

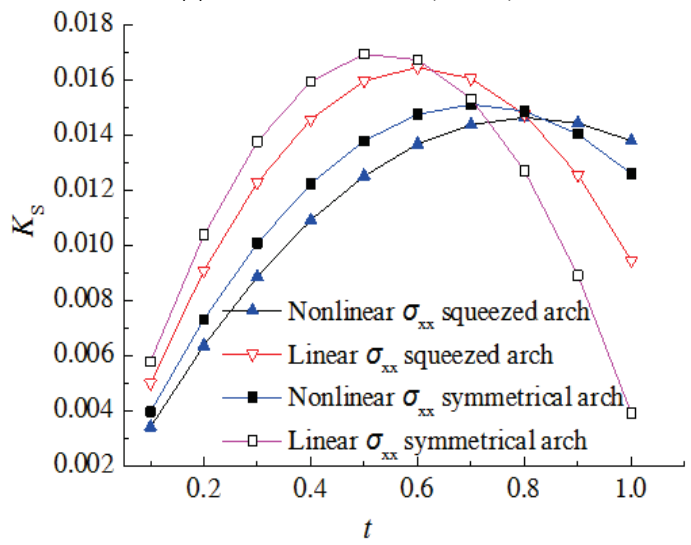

(b) Different thickness $t$ of the stress arch $(i=0.3)$

Figure 6 Variation law of the load bearing coefficient $K_{S}$ of the stress arch structure

When the fractured interval was fixed, the symmetrical stress arch and squeezed arch structure of thick strata kept higher load bearing capacity and played the main carrying function in the multiple layers. The distribution of the stress affected the load bearing capacity of the fractured strata structure. When the boundary horizontal stress was linearly distributed, the structure could reach the maximum load bearing capacity with smaller thickness of the stress arch.

For the hinged structure, the blocks kept surface contacting in small range or point contacting. In general condition, the thickness of the stress $\operatorname{arch} t<0.5$. According to Eq. (18), when the parameters satisfied $0.5 t+\frac{\sin \alpha_{2}-0.5 \sin \alpha_{1}}{i}>1$, the load bearing coefficient was $K_{\mathrm{S}}>0$. Considering the example where $t=0.4, \alpha_{1}=$ $5^{\circ}, \alpha_{2}=15^{\circ}$, the hinged structure could carry load efficiently when the block size $i$ was less than 0.3 . Hence, the load carrying capacity was determined by the block contacting state, rotating angle and block size.

According to the mining footage of No. 1 panel of Shanwan Mine, the working face was advanced $10 \mathrm{~m}$ each time in the simulation. As shown in Fig. 7, the immediate roof $I_{1}$ initially caved with the working face advancing 30 $\mathrm{m}$. The global pressure-arch was formed in the $B_{1}-B_{5}$ strata and the principle stress was transferred to the arch foots.

In the basic roof $B_{1}$ sliding instability occurred with the working face advancing $50 \mathrm{~m}$, two types of stress field were formed in the overlying strata. The outer was the global pressure-arch of the non-fractured zone in the surrounding rock. The arch top was mainly formed by the horizontal principle stress. The load of the upper strata acted on the arch top and was delivered through the concentrated horizontal stress to the arch waist. The inner was the symmetrical stress arch in each stratum under the inner boundary of the global pressure-arch. The horizontal principle stress distributed in the arch top in mid-span of each strata, enough horizontal stress was the essential condition to form the pressure-arch.

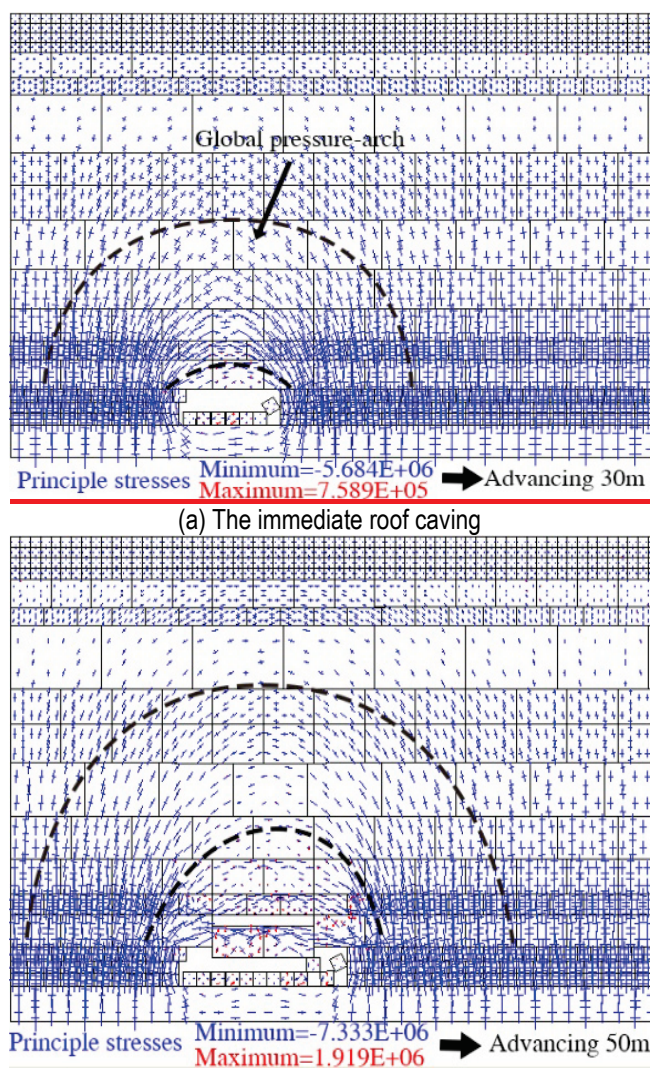

(b) The basic roof caving

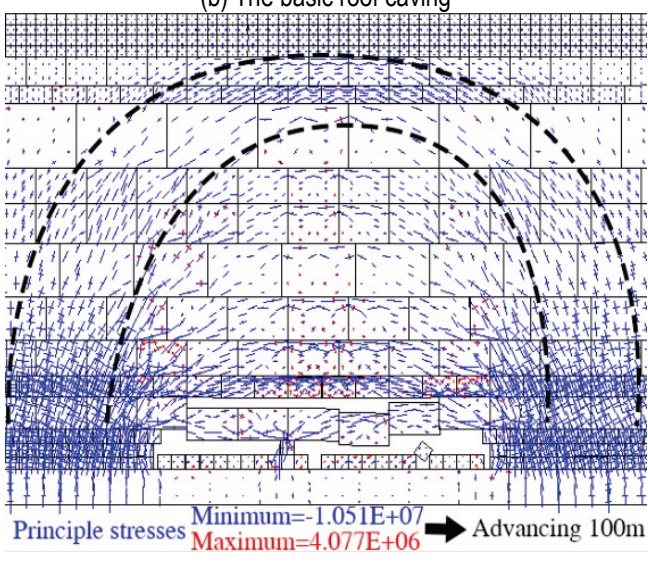

(c) The key blocks of the basic roof and global pressure-arch

Figure 7 Evolution process of pressure-arch and instability of the lower roof

The rear hanging blocks of the basic roof slid with unequal displacement by the friction and the step structure was formed, the principle stress in the main key block appeared arching characteristic by delivering from the coal face to the mined out area. The monitoring data of the vertical stress on each stratum were shown in Fig. 8. After initial caving of the immediate roof, the lower stress area formed in the $B_{1}$ and $B_{2}$ stratum under the inner boundary of the global pressure-arch, the $B_{6}$ and $B_{7}$ strata beyond the pressure-arch kept in-situ stress state. The global pressure- 
arch carried part load of the upper strata and self-weight, the arch feet were located in the increased stress area of the surrounding rock.

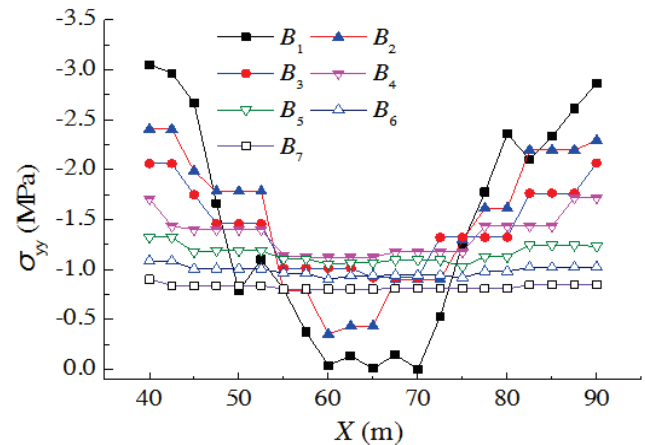

(a) The immediate roof caving

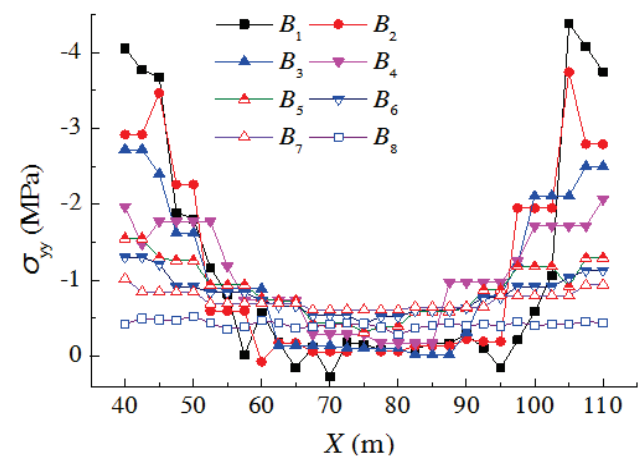

(b) The basic roof caving

Figure 8 Variation law of the vertical stress $\sigma_{y y}$ on each stratum

The global pressure-arch developed upward and reached the $B_{7}$ stratum after the basic roof caving. The increased load applied on the pressure-arch led to the higher vertical stress in the arch feet. Under the inner boundary of the global pressure-arch, the lower stress area extended, the resistance of the support increased for carrying the weight of this area. The roof weighting was determined by the basic roof near the mining area and performed as normal weighting stage.

As shown in Fig. 9a, the roof weighting was caused by the breaking of the $B_{2}$ stratum. With the working face advancing, the symmetrical stress arch in each stratum under the global pressure-arch experienced instability, the weighting interval varied from 10-30 $\mathrm{m}$, and the long/short and strong/weak weighting was induced periodically. The arching distribution of the principle stress caused the difference of the fractured position between each stratum, the span of the strata increased gradually. The instability of the upper strata with smaller span affected a larger range, and the strong weighting with short interval was induced.

The equilibrium structure of the fractured strata was formed by the squeezing and gripping of the rotated blocks, as shown in Figs. 9c to 9e. The significant arching effect of the principle stress appeared in the $B_{4}$ strata, the squeezed arch structure was formed with the front arch foot located in the bedrock at mining face side and the latter arch foot located in the compacted rock waste. The $B_{2}$ and $B_{3}$ strata were broken periodically and the hinged structure was formed, the principle stress was delivered as half arch in the front block and kept horizontal delivering in the rear block. The resistance of the support was increased by the rotation of the middle and lower strata, the weak weighting with long interval was induced.

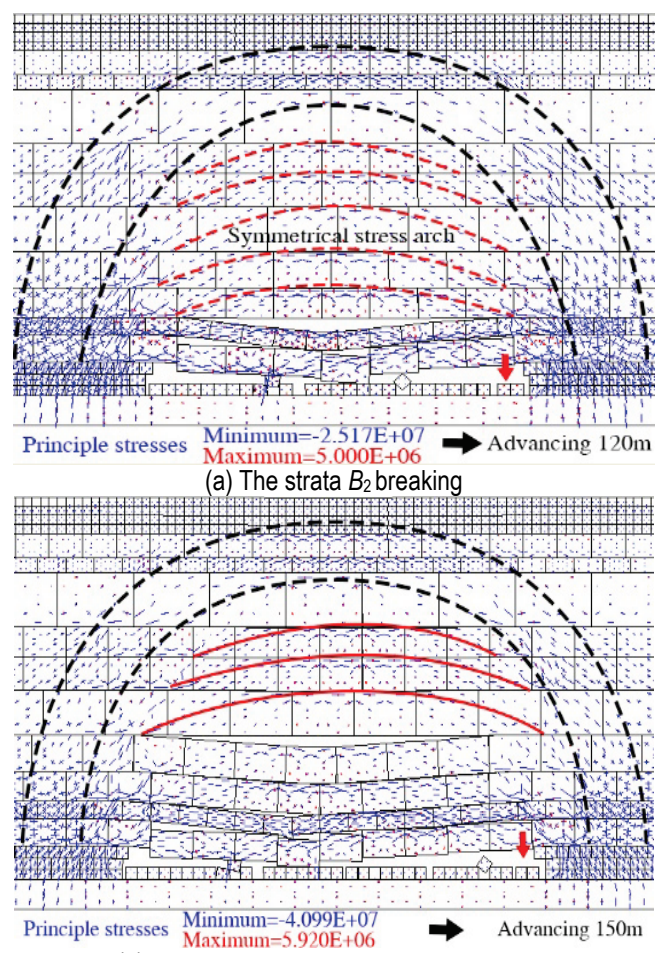

(b) The strata $B_{3}$ and $B_{4}$ combined breaking

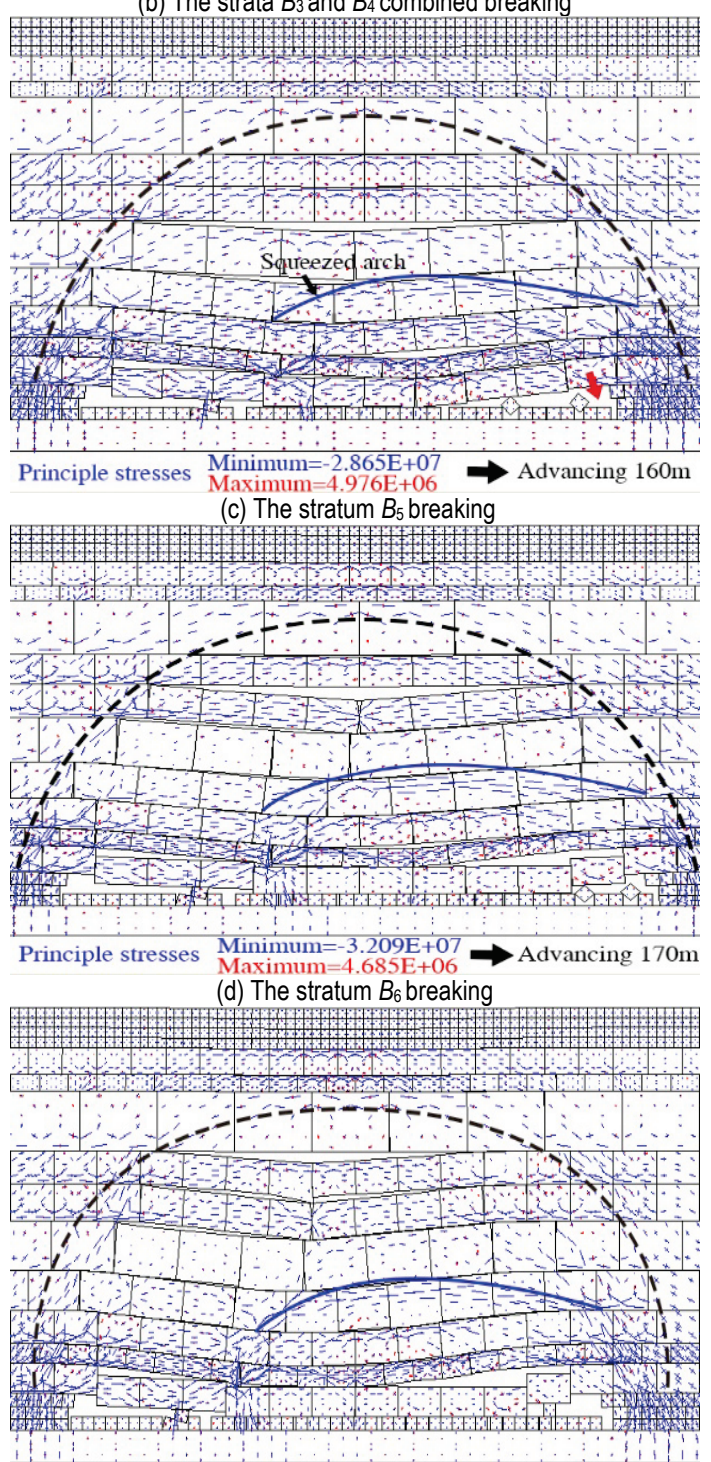

Principle stresses Minimum $=-3.569 \mathrm{E}+07$

(e) The stratum $B_{7}$ breaking

Figure 9 Evolution law of the structure of overlying strata 
As shown in Fig. 10, with the working face advancing $150 \mathrm{~m}$, the $B_{3}$ and $B_{4}$ strata were broken together, the outer boundary of the global pressure-arch developed into the loose sand layer, which resulted in the subsidence of 0.20 $\mathrm{m}$ on ground. With successive instability of the symmetrical stress arch in each stratum under the inner boundary of the global pressure-arch, the subsidence caused by single stratum breaking increased gradually, the subsidence for $B_{7}$ stratum breaking was greater than the accumulated value of $B_{1}-B_{4}$ strata breaking. The instability of the symmetrical stress arch in upper strata was the main cause of ground subsidence.

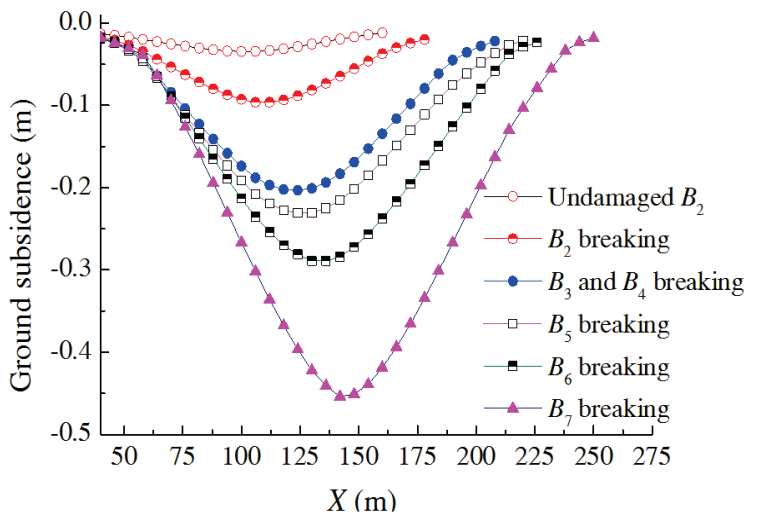

Figure 10 Subsidence characteristics curves of the overlying strata breaking

As shown in Fig. 11a, the global pressure-arch covered the loose sand layer and the subsidence basin was formed. As shown in Fig. 11b, a new global pressure-arch was reformed between the working face side and the caving compacted rock. The squeezed arch structure was formed in $B_{3}-B_{5}$ strata under the inner boundary of the global pressure-arch. In the hinged structure of $B_{2}$ stratum, the rotation of the block led to sliding instability of the basic roof. Alternated instability of the squeezed arch structure and the hinged structure induced the long/short and strong/weak weighting again.

The arching effect of the principle stress ensured the formation of the load bearing structure of overlying strata. For underground excavation in the laminated rock mass, a global pressure-arch with elevated stress was observed sustaining the weight of the overburden and providing the natural shield over the mining field, below the pressurearch was a group of local voussoir beam arches formed to transfer the weight of each layer to the abutments [6]. The macro-stress shell also existed in the rock surrounding for a fully mechanized top-coal caving face in deep mining, within the low-stress zone inside the stress shell, the voussoir beam structure only bore parts of the load from the strata [19-22].

Similarly, in the initial stage of shallow coal mining, the global pressure-arch was formed in the surrounding rock, under the inner boundary of the pressure-arch, the load of each stratum was carried by the symmetrical stress arch. However, the difference was that the pressure-arch would develop to the ground, the successive instability of the symmetrical stress arch with unequal span made different weighting interval. After total instability of the symmetrical stress arch, the latter arch feet of the pressurearch moved into the caving compacted rock, alternated instability of the squeezed arch and the hinged structure induced cyclic occurrence of the long/short and strong/weak weighting.

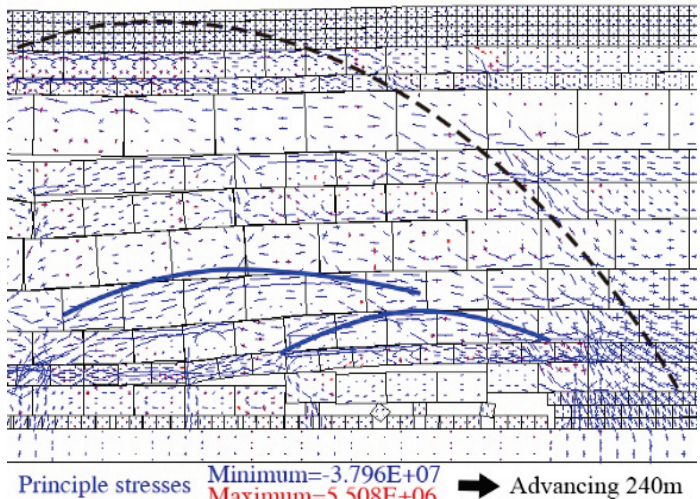

(a) Formation of the subsidence basin

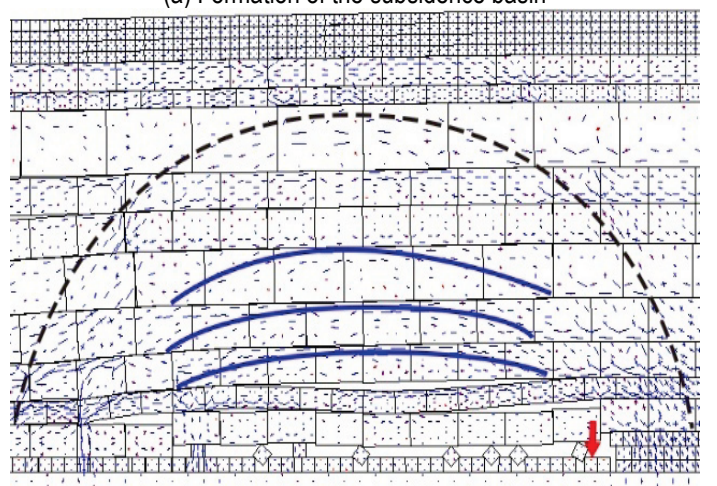

Principle stresses $\begin{aligned} & \text { Minimum }=-6.516 \mathrm{E}+07 \\ & \text { Maximum }=5.177 \mathrm{E}+06\end{aligned} \rightarrow$ Advancing $300 \mathrm{~m}$ (b) The pressure-arch advancing

Figure 11 Recombination characteristics of the structure of overlying strata

The equilibrium structure was formed by gripping of the rotated strata block, the evolution and recombination of the block structure caused the strong and weak changing of the support resistance. Considering the influencing factors of mining height, block size and rotating angle, a series of mechanical models were established in analyzing the stability of roof structure [10-12], but these models ignored the difference of the load bearing capacity of the strata structure. Affected by the contacting state of the blocks and the arching principle stress, only satisfying the limited condition of contacting range, rotating angle and boundary horizontal stress distribution, the hinged structure of the fractured strata could carry load efficiently. The load bearing capacity of the symmetrical stress arch and the squeezed arch structure depended on the maximum horizontal stress, and the load bearing coefficient was affected by the block size and boundary stress distribution.

The global pressure-arch in the non-fractured zone functioned as a main load bearing structure in the multiple layers rock, the single pressure-arch in the fractured blocks was located under the global pressure-arch. The global pressure-arch could be regarded as protected shell to the single pressure-arch, the fractured structure of roof in the single pressure-arch also carried part load of the upper strata. Instability of the global pressure-arch led to caving of the roof in the single pressure-arch, the compound instability of the two types of pressure-arch would cause the strong roof weighting.

For shallow long wall mining, the initial ground subsidence was induced when the pressure-arch developed 
into the loose sand layer, the successive instability of the symmetrical stress arch was the main cause of large scale ground subsidence, and the failure of stress arch structure in the upper strata could aggravate the formation of the subsidence basin.

\section{CONCLUSIONS}

The evolution of the pressure-arch affected the stability of the surrounding rock, each stratum appeared with different structure characteristic under the pressurearch. To reveal the evolution characteristics of the overlying strata structure, taking Shangwan Mine in Shendong Mining Area as background, considering the arching property of the stress, the mechanical models of different mining stages were proposed and the differences of the load bearing capacity of different pressure-arch and its influencing factors were discussed. The conclusions were listed as the following:

(1) The symmetrical stress arch, the squeezed arch or the hinged structure of the strata blocks can be formed by gripping of the horizontal stress, the load bearing capacity of the structure is affected by the factors of rotating angle, contacting range, boundary stress distribution and block size. Only satisfying the limited condition, the hinged structure can carry load efficiently. The symmetrical stress arch and the squeezed arch structure play a major role in load bearing.

(2) The action of the pressure-arch in the surrounding rock makes different fractured positions and span of the strata. Under the inner boundary of the pressure-arch, the successive instability of the symmetrical stress arch induces alternated strong and weak roof weighting. New pressure-arch is reformed when the caving rock is compacted in the mined-out area, the recombining evolution of the squeezed arch and the hinged structure make cyclic strong and weak roof weighting.

(3) During shallow coal mining, the pressure-arch can develop into the loose sand layer and induce initial subsidence. Further subsidence is caused by successive instability of the symmetrical stress arch. The instability of the load bearing structure of arching stress in the upper strata is the main cause of strong roof weighting and forming the subsidence basin.

The fractured strata structure along the striking direction of the working face is representative, which reflects the macro regulation of strata movement. However, under the action of mining stress and rock joints, there are differences of mechanical and engineering responses in the strata in different mining direction, so the stress evolution rules in different mining direction need to be further studied.

\section{Acknowledgements}

This work was financially supported by the National Natural Science Foundation of China (51774112; 51474188; 51074140), the International Cooperation Project of Henan Science and Technology Department (182102410060), the Doctoral Fund of Henan Polytechnic University (B2015-67), the Research Fund of State and Local Joint Engineering Laboratory for Gas Drainage \& Ground Control of Deep Mines (Henan Polytechnic
University) (G201614) and Taihang Scholars Program. All these are gratefully appreciated.

\section{Appendix}

\begin{tabular}{|c|c|}
\hline Symbol & The meaning of the symbol \\
\hline$M$ & Thickness of the coal seam \\
\hline$\Sigma h$ & Thickness of the immediate roof \\
\hline$K_{\mathrm{p}}$ & Rock bulking factor \\
\hline$\Delta$ & Displacement of the block $K_{\mathrm{A}}$ \\
\hline$\alpha$ & Rotating angle of the broken blocks $K_{\mathrm{A}}, G_{\mathrm{A}}, G_{\mathrm{B}}$, and $B_{\mathrm{D}}$ \\
\hline$\alpha_{1}$ & Rotating angle of the block $G_{\mathrm{A}}$ \\
\hline$\alpha_{2}$ & Rotating angle of the block $G_{\mathrm{B}}$ \\
\hline$T$ & Horizontal thrust \\
\hline$\sigma_{x x}$ & Horizontal stress \\
\hline$h$ & Distributed height of the horizontal stress \\
\hline$\sigma_{\mathrm{m}}$ & Maximum horizontal stress \\
\hline$x$ & Coordinate position of the horizontal stress \\
\hline$X_{\mathrm{T}}$ & Function position of the horizontal thrust \\
\hline$b$ & Variable parameter of the horizontal stress equation \\
\hline$L$ & Length of the broken block \\
\hline$H$ & Thickness of the broken block \\
\hline$H_{\mathrm{Z}}$ & Thickness of the overburden layer \\
\hline$\Sigma M_{\mathrm{A}}$ & Resultant moment at point $\mathrm{A}$ \\
\hline$T=\frac{\sigma_{\mathrm{m}} h}{b+1}$ & Resultant moment at point B \\
\hline$\Sigma M_{\mathrm{C}}$ & Resultant moment at point $\mathrm{C}$ \\
\hline$\Sigma M_{\mathrm{N}}$ & Resultant moment at point $\mathrm{N}$ \\
\hline$\Sigma M_{\mathrm{O}}$ & Resultant moment at point $\mathrm{O}$ \\
\hline$\Sigma F_{y}$ & Vertical resultant force \\
\hline$F_{\mathrm{A}}$ & Support force of the broken block $G_{\mathrm{A}}$ \\
\hline$F_{\mathrm{B}}$ & Support force of the broken block $G_{\mathrm{B}}$ \\
\hline$F_{\mathrm{C}}$ & Support force of the broken block $B_{\mathrm{C}}$ \\
\hline$F_{\mathrm{D}}$ & Support force of the broken block $B_{\mathrm{D}}$ \\
\hline$F_{\mathrm{E}}$ & Support force of the broken block $B_{\mathrm{E}}$ \\
\hline$F_{\mathrm{M}}$ & Support force of the broken block $B_{\mathrm{M}}$ \\
\hline$F_{\mathrm{N}}$ & Support force of the broken block $B_{\mathrm{N}}$ \\
\hline$Q_{\mathrm{A}}$ & Shear force of the contact surface at point $A$ \\
\hline$Q_{\mathrm{B}}$ & Shear force of the contact surface at point B \\
\hline$Q_{\mathrm{C}}$ & Shear force of the contact surface at point $\mathrm{C}$ \\
\hline$Q_{\mathrm{M}}$ & Shear force of the contact surface at point $M$ \\
\hline$Q_{\mathrm{N}}$ & Shear force of the contact surface at point $\mathrm{N}$ \\
\hline$Q_{\mathrm{E}}$ & Shear force of the contact surface at point $\mathrm{E}$ \\
\hline$P_{\mathrm{A}}$ & Simplified vertical force of the broken block $G_{\mathrm{A}}$ \\
\hline$P_{\mathrm{B}}$ & Simplified vertical force of the broken block $G_{\mathrm{B}}$ \\
\hline$P_{\mathrm{C}}$ & Simplified vertical force of the broken block $B_{\mathrm{C}}$ \\
\hline$P_{\mathrm{D}}$ & Simplified vertical force of the broken block $B_{\mathrm{D}}$ \\
\hline$P_{\mathrm{E}}$ & Simplified vertical force of the broken block $B_{\mathrm{E}}$ \\
\hline$P_{\mathrm{M}}$ & Simplified vertical force of the broken block $B_{\mathrm{M}}$ \\
\hline$P_{\mathrm{N}}$ & Simplified vertical force of the broken block $B_{\mathrm{N}}$ \\
\hline$P$ & Simplified vertical force of the broken block $K_{\mathrm{A}}$ \\
\hline$\varphi$ & Internal friction angle \\
\hline$\gamma$ & Average unit weight \\
\hline$f$ & Efficient bearing load \\
\hline$i$ & Ratio of the thickness to the length of the block \\
\hline$t$ & $\begin{array}{l}\text { Ratio of the distributed height of the horizontal stress to the } \\
\text { block thickness }\end{array}$ \\
\hline$K_{S}$ & Load bearing coefficient \\
\hline
\end{tabular}

\section{REFERENCES}

[1] Zhang, J. C. \& Peng, S. P. (2005). Water inrush and environmental impact of shallow seam mining. Environmental Geology, 48(8), 1068-1076. https://doi.org/10.1007/s00254-005-0045-8

[2] Zhang, D. S., Fan, G. W., Ma, L. Q., \& Wang, X. F. (2011). Aquifer protection during longwall mining of shallow coal seams: A case study in the Shendong Coalfield of China. International Journal of Coal Geology, 86(2-3), 190-196. https://doi.org/10.1016/j.coal.2011.01.006

[3] Xu, J. L., Ju, J. F., \& Zhu, W. B. (2014). Supports crushing types in the longwall mining of shallow seams. Journal of China Coal Society, 39(8), 1625-1634. https://doi.org/10.13225/j.cnki.jccs.2014.9006 
[4] Wang, G., Luo, H. J., Wang, J. R., Tian, F. C., \& Wang, S. (2016). Broken laws of key strata on strata behaviors in large height fully-mechanized face of nearly shallow coal seam. Journal of China University of Mining \& Technology, 45(3), 469-474. https://doi.org/10.13247/j.cnki.jcumt.000509

[5] Li, C. C. (2006). Rock support design based on the concept of pressure arch. International Journal of Rock Mechanics \& Mining Sciences, 43(7), 1083-1090. https://doi.org/10.1016/j.ijrmms.2006.02.007

[6] He, L. \& Zhang, Q. B. (2015). Numerical investigation of arching mechanism to underground excavation in jointed rock mass. Tunnelling \& Underground Space Technology, 50, 54-67. https://doi.org/10.1016/j.tust.2015.06.007

[7] Shabanimashcool, M. \& Li, C. C. (2015). Analytical approaches for studying the stability of laminated roof strata. International Journal of Rock Mechanics \& Mining Sciences, 79, 99-108. https://doi.org/10.1016/j.jijmms.2015.06.007

[8] Mazor, D. B., Hatzor, Y. H., \& Dershowitz, W. S. (2009). Modeling mechanical layering effects on stability of underground openings in jointed sedimentary rocks. International Journal of Rock Mechanics \& Mining Sciences, 46(2), 262-271. https://doi.org/10.1016/j.jjmms.2008.04.001

[9] Tsesarsky, M. (2012). Deformation mechanisms and stability analysis of undermined sedimentary rocks in the shallow subsurface. Engineering Geology, 133(4), 16-29. https://doi.org/10.1016/j.enggeo.2012.02.007

[10] Yang, Z. L. (2010). Stability of nearly horizontal roof strata in shallow seam longwall mining. International Journal of Rock Mechanics \& Mining Sciences, 47(4), 672-677. https://doi.org/10.1016/j.jirmms.2010.03.001

[11] Ju, J. F. \& Xu, J. L. (2013). Structural characteristics of key strata and strata behaviour of a fully mechanized longwall face with $7.0 \mathrm{~m}$ height chocks. International Journal of Rock Mechanics \& Mining Sciences, 58(1), 46-54. https://doi.org/10.1016/j.jijmms.2012.09.006

[12] Huang, Q. X., Dong, B., \& Chen, S. S. (2016). Determination of roof pressure law and support resistance in the mining face with super-large mining height in approximate shallow coal seam. Journal of Mining \& Safety Engineering, 32(2), 175181. https://doi.org/10.13545/j.cnki.jmse.2016.05.012

[13] Liu, X., Song, G., \& Li, X. (2015). Classification of roof strata and calculation of powered support loads in shallow coal seams of China. Journal of the Southern African Institute of Mining \& Metallurgy, 115(11), 1113-1119. https://doi.org/10.17159/2411-9717/2015/v115n11a15

[14] Hu, H. F., Lian, X. G., \& Li, Y. (2016). Physical experiments on the deformation of strata with different properties induced by underground mining. Journal of Engineering Science and Technology Review, 9(1), 74-80. https://doi.org/10.25103/jestr.091.12

[15] Soni, A. K., Singh, K. K. K., Prakash, A., Singh, K. B., \& Chakraboraty, A. K. (2007). Shallow cover over coal mining: a case study of subsidence at Kamptee Colliery, Nagpur, India. Bulletin of Engineering Geology and the Environment, 66(3), 311-318. https://doi.org/10.1007/s10064-006-0072-z

[16] Helm, P. R., Davie, C. T., \& Glendinning, S. (2013). Numerical modelling of shallow abandoned mine working subsidence affecting transport infrastructure. Engineering Geology, 154(154), 6-19. https://doi.org/10.1016/j.enggeo.2012.12.003

[17] Salmi, E. F., Nazem, M., \& Karakus, M. (2017). The effect of rock mass gradual deterioration on the mechanism of postmining subsidence over shallow abandoned coal mines. International Journal of Rock Mechanics \& Mining Sciences, 91, 59-71. https://doi.org/10.1016/j.jirmms.2016.11.012

[18] Cui, X. M., Gao, Y. G., \& Yuan, D. B. (2014). Sudden surface collapse disasters caused by shallow partial mining in Datong coalfield, China. Natural Hazards, 74(2), 911-929. https://doi.org/10.1007/s11069-014-1221-5
[19] Wang, S. R., Li, N., Li, C. L., Zou, Z. S., \& Chang, X. (2015). Instability mechanism analysis of pressure-arch in coal mining field under different seam dip angles. DYNA, 90(3), 279-284. https://doi.org/10.6036/7530

[20] Xie, G. X., Chang, J. C., \& Yang, K. (2009). Investigations into stress shell characteristics of surrounding rock in fully mechanized top-coal caving face. International Journal of Rock Mechanics \& Mining Sciences, 46(1), 172-181. https://doi.org/10.1016/j.jijmms.2008.09.006

[21] Wang, S. R., Wu, X. G., Zhao, Y. H., \& Hagan P. (2018). Mechanical performances of pressure-arch in thick bedrock during shallow coal mining. Geofluids, 2018, 1-13. https://doi.org/10.1155/2018/2419659

[22] Zhao, Y. H., Wang, S. R., Zou, Z. S., Ge, L. L., \& Cui, F. (2018). Instability characteristics of the cracked roof rock beam under shallow mining conditions. International Journal of Mining Science and Technology, 28(3), 437-444. https://doi.org/10.1016/.j.jmst.2018.03.005

\section{Contact information}

Yanhai ZHAO, Postgraduate

School of Civil Engineering, Henan Polytechnic University,

2001 Century Avenue, Jiaozuo, Henan Province, 454003, China

E-mail: qingtingnba@163.com

\section{Shuren WANG, PhD, Professor}

(Corresponding author)

1) International Joint Research Laboratory of Henan Province for Underground Space Development and Disaster Prevention, Henan Polytechnic University, 2001 Century Avenue, Jiaozuo, Henan Province, 454003, China

2) School of Mining Engineering, University of New South Wales, Sydney, NSW 2052, Australia

E-mail: w_sr88@163.com

\section{Youfeng ZOU, PhD, Professor}

School of Surveying and Land Information Engineering,

Henan Polytechnic University,

2001 Century Avenue, Jiaozuo, Henan Province, 454003, China

E-mail: zouyf@hpu.edu.cn

Xuchun WANG, PhD, Professor

School of Civil Engineering, Qingdao University of Technology,

11 Fushun Road, Qingdao, Shandong Province, 266033, China

E-mail: xuchun_wang@263.net

Bingqiang HUANG, PhD, Professor

Nanning Exploration \& Survey Institute,

31-1 Chahuayuan Road, Nanning, Guangxi Province, 530022, China

E-mail: Bingqiang_huang@163.com

Xingui ZHANG, PhD, Professor

College of Civil Engineering \& Architecture, Guangxi University,

100 Daxue Road, Nanning, Guangxi Province, 530004, China

E-mail: xgzhangchn@163.com 